\title{
The dynamics of entry for digital platforms in two-sided markets: a multi-case study
}

\author{
Jørgen Veisdal $^{1}$
}

Received: 14 October 2019 / Accepted: 10 February 2020 / Published online: 27 February 2020

(C) The Author(s) 2020

\begin{abstract}
Motivating buyers and sellers to join an empty platform is thought to be a key challenge for firms attempting to launch digital platforms in two-sided markets. According to predictions from extant literature, 'no one joins until everyone joins'. The phenomenon is often referred to as the "chicken-and-egg problem". This study investigates the phenomenon in an exploratory multi-case study of ten startup technology firms operating digital platforms in two-sided markets. The study finds that the firms entered their markets using a variety of strategies distinguishable by strategic, relational and temporal factors. A conceptual framework is proposed which distinguishes the firms' strategies along these dimensions. In addition, a cross-case discussion of the dynamics of the firms' strategies is provided. Deductively, the findings contribute to establishing an empirical grounding for predictions from extant literature. Inductively, the findings contribute preliminary managerial implications as well as propositions for further research on entry strategies for digital platforms in two-sided markets.
\end{abstract}

Keywords Multi-sided platforms $\cdot$ Case study research $\cdot$ Entry $\cdot$ Networks \& ecosystems $\cdot$ Business models $\cdot$ Strategy execution

JEL classifications L86 $\cdot$ Information and Internet Services $\cdot$ Computer Software

\section{Introduction}

"We didn't have anything to offer, but at least they had a pain that was interesting enough that it should be possible to convince them" - Patrik Berglund, CEO of Xeneta

Many of the largest and most influential firms in today's economy operate digital platform businesses in two-sided markets dominated by network externalities, so-called "network effects" (Katz and Shapiro 1985; Rochet and Tirole 2003; Alt and Zimmermann 2019). Acting as intermediaries between two or more groups of participants with interdependent demands, such firms' main market function is typically

Jørgen Veisdal

jorgen.veisdal@ntnu.no

1 Department of Industrial Economics and Technology Management, Norwegian University of Science and Technology, Alfred Getz vei 1, 7491 Trondheim, Norway described as the facilitation of interactions and transactions between producers of goods on one side and buyers or users on the other (e.g. Hagiu 2006; Boudreau and Jeppesen 2015). Examples of various types of platforms range from the twosided platforms of Amazon's Marketplace (sellers and buyers), Apple and Google's "app" stores (developers and users), services such as Airbnb (hosts and guests) and Uber (drivers and passengers) to multi-sided platforms such as those offered by Facebook, Google Search and YouTube (content providers, users and advertisers).

The successful entry of a digital platform provider in a twosided market is said to rely on that firms' provision of products and/or services which increase the platform's attractiveness to buyers/users (McIntyre and Srinivasan 2017; Alt and Zimmermann 2019). In providing a valuable transportation service to passengers, a ride-sharing platform such as Uber is reliant on its ability to first attract a sufficient number of drivers, which in turn are more likely to join platforms with already established demand from passengers. Because of this, firms looking to establish platform businesses in two-sided markets can prior to entry be faced with a "chicken-and-egg" problem (Caillaud and Jullien 2003; Kyprianou 2018), the socalled "circular conundrum" (Spulber 2010) if the 
expectations among potential end-users and suppliers/ complementors are unfavorable (Hagiu 2006).

Historically, researchers have focused on the size of the socalled 'installed base' as the most strategically valuable asset in networked industries (Evans and Schmalensee 2007). Related, there has been a tendency in extant research to consider the availability of products and/or services to a platform as an exogenously determined fact rather than a construct that is susceptible to (and ultimately dependent on) strategic manipulation. This should be considered a key limitation to our current understanding of how platforms launch (McIntyre and Subramaniam 2009; McIntyre and Srinivasan 2017). Thus far in research that has investigated platform entry, one seeming consensus has been that platform owners should pursue aggressive monetary strategies for attracting buyers in order to motivate potential suppliers to join (Boudreau and Jeppesen 2015; Cennamo and Santalo 2013). Examples of such strategies often highlighted in extant literature include 1) setting low prices to one side of the market first and making money on the other side later (e.g. Rochet and Tirole 2003; Armstrong 2006) and 2) using licensing strategies and/or exclusive contracts (e.g. Armstrong and Wright 2007; Hagiu 2009). Additional strategies often discussed include offering first-party content (Hagiu and Spulber 2013), ensuring compatibility with the preferences of suppliers/an installed base on existing platforms (Schilling 2002) and manipulating the expectations of potential participants by pre-announcing the service before it is actually viable (Bhargava 2014).

This paper examines the phenomenon of supplier recruitment to platforms in two-sided digital markets prior to their establishment of network effects. This is done through an abductive, exploratory multi-case study. The goal of the study was to provide an overview of how two-sided platforms can emerge as the consequence of platform firms' supply-side recruitment strategies, and so expand of the scope of nonpricing related research on entry strategies in markets ultimately dominated by network effects. The primary source of data for the study was interviews with managers of established start-up firms operating digital platforms in two-sided markets. The research question guiding the investigation was: How do managers of nascent digital platforms in two-sided markets strategize to recruit early suppliers?

The paper makes three contributions to the literature. Primarily, it provides a grounded empirical overview and framework describing the dynamics of non-pricing related entry strategies employed by firms to attract suppliers to platforms prior to the establishment of network effects. Secondarily, as a result of the preliminary analysis of the firms' entry strategies, an analysis of the dynamics of early supplier recruitment is provided, highlighting relevant managerial considerations as well as contextual and firm-specific factors affecting the success of the firms' strategies. Finally, given these findings, the paper provides preliminary managerial implications as well as motivates an agenda for further theory building on non-pricing related entry strategies for newly established platforms in two-sided markets. In the following section, the theoretical context in which the findings of the study were interpreted will be presented. In the next sections, the methodology used to capture and analyze the data is outlined, along with the findings and the analysis that emerged from this process, respectively. The discussion section that follows re-examines novel observations from the findings contrasted against the relevant theoretical context. The paper concludes with a summation of the findings of the study, preliminary managerial implications and an agenda for further research.

\section{Theoretical context}

\begin{abstract}
"Most often prospective users of new services will not know how much utility they can obtain from the service until after they start using it." - Halaburda and Yahezkel (2013)
\end{abstract}

In traditional value chains, firms acquire inputs from suppliers and bundle them into products and services, which are offered to buyers through activities such as marketing, distribution and customer service (Porter 1985). In two- and multisided markets, platform firms operate businesses which act as intermediaries between multiple groups of participants who are looking to benefit from interacting with other participants with complementary needs. While the definition of what constitutes a 'platform' in two- or multi-sided markets varies, two general forms have previously been identified in the literature: two-sided and multi-sided platforms (Otto and Jerke 2019). Whereas two-sided platforms mediate transactions and/or interactions between two groups of users (e.g. buyers and sellers), multi-sided platforms (MSPs) intermediate between at least three groups (Hagiu 2009) such as e.g. businesses, users, software developers and advertisers.

The fundamental premise of platform-mediated networks is that users place a higher value on platforms with a larger number of participants (Cennamo and Santalo 2013) with whom they can interact. In extant conceptualizations of both two- and multi-sided platforms, potential participants' level of uncertainty about the usefulness of a new platform is in other words thought to be highly dependent on the level of adoption by other participants with complementary interests (Halaburda and Yahezkel 2013). For instance, in a two-sided market, a new platform offering contactless payments may increase merchants' profitability, but merchants will only become aware of this increased utility when a significant number of buyers adopt the platform and begin completing 
transactions. Likewise, buyers may find a new payment service more efficient and easier to use but be unaware of this fact until merchants accept the new service as a valid method of payment. The archetypal initial strategic challenge in twosided markets is hence breaking this initial "circular conundrum" (Spulber 2010) by convincing one group to join first, before approaching the other group with a proposition which highlights the value of interacting and/or transacting with members of the first group who are already on the platform.

An alternative way of breaking the circular conundrum is for a platform owner to add additional groups whose participation decisions are not wholly contingent on the existing number of participants in the market (Boudreau and Jeppesen 2015), i.e. creating a multi-sided platform. For our example above, the contactless payment platform may implement third-party software which allows buyers to browse the merchant's goods online, which on its own may attract enough merchants to the solution so that the circular conundrum is broken. Providers of such third-party services are commonly referred to as "complementors" (De Reuver et al. 2018). In both two- and multi-sided markets, the link between the actions of participants from one group (such as buyers) on the expected utility of participants from another group (such as merchants) is what is commonly referred to as indirect "crossgroup" network externalities ("effects") (Caillaud and Jullien 2001, 2003).

The two core groups of participants in both two- and multisided markets are commonly referred to as demand- and supply-side participants. In most markets, demand-side participants are the receivers of services provided primarily by supply-side participants. Conversely, supply-side participants are the receivers of some other (often monetary) value provided by demand-side participants. In multi-sided markets, thirdparty participants ("complementors") provide services which complement the services provided by either demand- or supply-side participants, or both. In our example above, the third-party software service complements the offering of the supply-side (merchants), helping to attract demand-side participants (buyers). On advertising-supported platforms such as YouTube, third-party advertisers complement (subsidize) the value of the attention provided by demand-side participants (viewers) for supply-side participants (uploaders). From the perspective of participants, platforms act as independent, third-party intermediaries of interactions and/or transactions between the various groups.

In extant conceptualizations, the decisions of suppliers of goods and services to join a platform are thought to mainly be the function of their expectations about the level of participation on the other side(s) of the market (Fuentelsaz et al. 2015). Much of the focus of platform research has thus far therefore revolved around formulating strategies for ensuring that potential participants' expectations are favorable (Hagiu and Spulber 2013). The formalized economics literature has here mainly emphasized the role of pricing strategies (e.g. Rochet and Tirole 2003; Armstrong 2006; Caillaud and Jullien 2003; Hagiu 2006; Weyl 2010). Other related literature dealing with how to ensure favorable expectations have included investigations of openness decisions (Boudreau 2010; Eisenmann et al. 2009), content strategies (Boudreau and Jeppesen 2015; Carlton et al. 2010; Farrell and Katz 2000; Hagiu and Spulber 2013) and expectations from the point of view of neoclassical economic theory (e.g. Rochet and Tirole 2003; Hagiu 2006; Halaburda and Yahezkel 2013; Hagiu and Halaburda 2014). Critics of this "IO" (industrial organization) approach to platform research have emphasized the tendency of such studies to 1) assume the presence of network externalities and other two-sided market characteristics exogenously (McIntyre and Subramaniam 2009); and 2) treat the relationships between participants and platform firms as "black-boxes" (Srinivasan and Venkamatran 2010), and so tend to focus mainly on the impact of available supply on market outcomes; and 3) overlook process dynamics and governance activities beyond pricing (Gawer 2014; Wareham et al. 2014). This despite a seemingly strong consensus among management scholars that the management of supply is particularly beneficial in network markets (Kapoor and Lee 2013). Much of extant research hence effectively excludes the possibility of strategic positioning and other phenomena commonly studied in management research (McIntyre and Srinivasan 2017). As a result, extant literature holds limited value for managers attempting to strategically design and govern platform businesses for and during entry (Gawer 2014). Although a nascent stream of strategy research has begun tackling this deficit, including studying the competitive advantage of entry timing (Eisenmann 2006; Schilling 2002), incumbent advantages such as firm size, platform features and relative quality (Liebowitz and Margolis 1994; McIntyre 2011; Zhu and Ianisiti 2012), as of yet, much still remains to be known about how firms go about successfully entering two- and multi-sided markets (McIntyre and Srinivasan 2017).

\section{Methodology}

\section{Research design and context}

In an effort to contribute to the nascent theoretical context presented above, an abductive, exploratory multi-case study design was chosen. Multi-case studies are particularly appropriate when there is relatively little theoretical precedent for a deductive study (Eisenhardt 1989; Yin 2009). They allow the researcher to recognize and evaluate relationships among constructs, and therefor gain new theoretical insights (Eisenhardt and Graebner 2007; Yin 2009). An exploratory multi-case study is particularly relevant for answering the research questions explored in this paper, as they relate to "how questions" 
such as how managers of firms went about formulating entry strategies for their respective markets (Eisenhardt 1989).

Ten established start-up firms from Norway participated in the study. The sample was chosen across multiple industries in order to allow for investigations into industry-independent constructs. The sample was chosen exclusively among Norwegian firms in order to limit the impact of variance stemming from macroeconomic and regulatory factors, and in order to make use of the summarized accounting records of the firms, which in Norway are publicly accessible. Established start-up firms were chosen in order to be able to examine the properties and relative effectiveness of the strategies employed by the firms, post hoc.

\section{Inclusion criteria}

For a firm to be considered for inclusion in the study, its platform had to be sufficiently 'established' so as to indicate that it had likely established a liquid enough market to permit sustainable growth (Ondrus et al. 2015) i.e. had overcome the potentially unfavorable expectations of early demand- and supply-side participants (Hagiu and Spulber 2013) and reached a so-called "critical mass" (Ondrus et al. 2015). This in order to ensure that some combination of whatever strategies the firms pursued had been successful. In practice, firms were considered "sufficiently established" if they had either 1 . Generated revenue from their platform business in the preceding year (i.e. began monetizing their service on one or both sides of their platform) or 2. The scope of the firms' operations included 20 or more employees at the time of the sampling. Fulfillment of either criteria qualified firms for inclusion in the study. The decision to not require both criteria was in order to enable inclusion of platforms who had yet to monetize their services, and/or had experienced rapid growth with a small organization. Fulfillment of either criteria was verified prior to sampling using data from the Norwegian financial database Proff ${ }^{1}$.

Additional criteria applied during sampling were:

- The firms' only major business activity had to be 'operating a platform in a two-sided market'. This in order to eliminate spillover effects from other business activities;

- The managers interviewed had to be working in the firms at the time of their founding. This to ensure that statements were first-hand accounts of what occurred;

Additionally, firms included had to be in a "start-up phase", in this study determined to mean that it was less than five calendar years since the founding of each firm. This in order to ensure quality in the data collected from managers during the interviews;

\footnotetext{
${ }^{1}$ Proff AS, 2019. Available at: http://www.proff.no
}

\section{Selection process}

After determining the research design and inclusion criteria, a search process commenced. First, a list of Norwegian start-up firms operating platforms in two-sided markets was compiled. The initial list contained 37 firms. After applying the inclusion criteria and completing a superficial financial review to ensure that each firm could be considered as sufficiently 'established', 19 firms remained. Managers in each firm were contacted via email for participation in the study. Of those contacted, five did not respond to the inquiry, two declined to participate and twelve agreed. Of the twelve that agreed, ten were available for interviews in the data collection period from December 2017 - February 2018.

\section{Sample}

The ten firms included in the study are listed in Table 1. All ten firms included in the study offered especially favorable settings for data collection. This because, of the eleven managers interviewed (one firm was represented by two managers for the interview), ten were also co-founders and so significantly involved in the firms' operations prior to, during and after the launch of their services. Nine of the managers interviewed were also CEO of their firm at the time of the interview. Other commonalities include nationality, of the eleven managers interviewed, all but one were native Norwegian citizens. Differences among the firms included the educational- and professional background of their founders. Six of the ten founders interviewed had university degrees in strategy, business and/or economics at a graduate-level, two in computer science and two had not pursued higher education. Four founders had experience from working in start-up companies, three from management consulting and two had no prior relevant work experience. Three founders had worked as suppliers in the same industry their firm operated in. The ten firms mostly operated in different industries, with the exception of two firms which both recruited graphic designers. All firms' main offices were located in Oslo at the time of the study. Two of the firms had international operations at the time of the study and eight had taken investments from angel investors, venture capital firms and/or corporate investors.

\section{Data collection}

The primary source of data gathered for the study was semistructured interviews, which is the most common method of data collection used in case-based research (e.g. Eisenhardt 1989). The interviews were conducted face to face in the firms' offices. Each interview lasted approximately one hour and was recorded. Every interviewee was informed about the purpose of the study and gave consent that the findings could be published. Prior to conducting the interviews, an interview guide was composed. 
Table 1 Overview of the ten firms included in the sample

\begin{tabular}{|c|c|c|c|c|c|}
\hline Firm & Acronym & Founded & $\begin{array}{l}\text { Value } \\
\text { proposition }\end{array}$ & $\begin{array}{l}\text { Supply-side } \\
\text { participants }\end{array}$ & $\begin{array}{l}\text { Demand-side } \\
\text { participants }\end{array}$ \\
\hline Graphiq & GQ & 2015 & Design services & Freelance designers & SMEs \\
\hline Konsus & KS & 2016 & $\begin{array}{r}\text { Marketing and } \\
\text { design tasks }\end{array}$ & $\begin{array}{l}\text { Freelance marketers } \\
\text { and designers }\end{array}$ & $\begin{array}{l}\text { SMEs and large } \\
\text { enterprises }\end{array}$ \\
\hline LearnLink & LL & 2014 & $\begin{array}{l}\text { Private tutoring } \\
\text { services }\end{array}$ & $\begin{array}{l}\text { Freelance private } \\
\text { tutors }\end{array}$ & $\begin{array}{c}\text { Parents of students in } \\
\text { secondary school }\end{array}$ \\
\hline Nabobil & NB & 2015 & $\begin{array}{r}\text { Car rental } \\
\text { services }\end{array}$ & Car owners & Consumers \\
\hline NyBy & NY & 2015 & Community tasks & Public employee & $\begin{array}{l}\text { Recipients of welfare } \\
\text { services }\end{array}$ \\
\hline TikkTalk & $\mathrm{TT}$ & 2016 & $\begin{array}{l}\text { Interpretation } \\
\text { service }\end{array}$ & Freelance interpreters & $\begin{array}{l}\text { Government } \\
\text { organisations and } \\
\text { SMEs }\end{array}$ \\
\hline Tise & TI & 2014 & $\begin{array}{l}\text { Social } \\
\text { marketplace }\end{array}$ & Consumer & Consumers \\
\hline Uninite & UN & 2016 & $\begin{array}{l}\text { Shared housing } \\
\text { matching }\end{array}$ & Property owners & Young adults \\
\hline WeClean & WC & 2015 & Cleaning service & Freelance Cleaners & SMEs \\
\hline Xeneta & $\mathrm{XE}$ & 2012 & $\begin{array}{l}\text { Freight price } \\
\text { benchmaking }\end{array}$ & $\begin{array}{l}\text { Buyers of freight } \\
\text { services }\end{array}$ & $\begin{array}{c}\text { Buyers and suppliers } \\
\text { of freight services }\end{array}$ \\
\hline
\end{tabular}

The guide consisted of a list of formal questions about the firms and their history, as well as open-ended questions about the founding of the firms and their operations. In addition to interviews, field notes documenting observations, insights, ideas and impressions were also recorded prior to, during and after the interviews. These were later used to supplement interview transcripts and to help confirm and reject emerging theoretical perspectives during the data analysis process.

To supplement the primary data source, secondary data from other sources was also collected. This for the purposes of triangulation (Yin 2014), which refers to the process of "self-consciously setting out to double check findings, using multiple sources and modes of evidence" to confirm qualitative findings (Miles and Huberman 1994 p. 234-235, cited in Patzelt et al. 2014). In practice, triangulation involves subjecting potential findings to "an onslaught of a series of imperfect measures" (Webb et al. 1965, cited in Patzelt et al. 2014) to corroborate findings generated from the primary data source(s). In this study, triangulation involved investigating the validity of verifiable findings relating to the firms entry strategies using information gathered from Internet searches, such as articles in publications about the firms and/or its cofounders, press releases/blog- and social media posts as well as archived versions of the firms' websites using the WayBack Machine on Archive.org ${ }^{2}$. In practice, these secondary sources of information were used mainly to supplement and corroborate information about the firms' communication to potential supply-side participants around the time of their platform's entry.

\footnotetext{
${ }^{2}$ Archive.org, 2019. WayBack Machine. Available at: http://www.proff.no
}

\section{Data analysis}

The overall analysis was structured according to the established procedures for grounded, theory-building research (Locke 2001; Miles and Huberman 1994; Strauss and Corbin 1990), following guidelines for constant comparison techniques (Glaser and Strauss 1967) and working recursively back and forth between the data and emerging theory (Patzelt et al. 2014). The core procedural guideline for the data analysis was to try to remain open-minded and "let the data speak" (Suddaby 2006). The audio recordings of each interview were first transcribed by the author and a research assistant. The analysis process consisted of three steps, using the so-called "Gioia-method" (Corley and Gioia 2004; Gioia et al. 2013, 1994; Pratt et al. 2006). First, first-order codes consisting of statements and descriptions were delineated from the texts. Next, the codes were grouped into sub-theoretical, then theoretical dimensions. Finally, the theoretical dimensions were grouped into aggregate theoretical dimensions which made up the core tenants of the findings of the study.

\section{Identifying first-order codes}

The first step of the analysis process consisted of a superficial analysis of each statement made in the interviews, so-called "open coding" (Locke 2001), looking to identify first-order codes (Van Maanen 1979) related to managers' descriptions of how and why they established their platforms, as well as managers' impressions of how and why early suppliers joined. Segments (sentences, paragraphs) of text were coded individually by hand and combined with other potentially relevant 
data such as field notes and information gathered from secondary sources (Yin, 2014). At this initial stage, focus was on identifying consistent issues, strategies, relationships and other themes that appeared across cases (Corley and Gioia 2006), using constant comparison techniques (Glaser and Strauss 1967). Examples of first-order codes uncovered during the initial analysis were "early supply-side recruitment strategy", "early value proposition for demand side" and "preferences of early suppliers". A total of 136 first-order codes containing 1188 references emerged from the coding process. As with all steps in the analysis process, the coding process could be described not as linear but as a "recursive, process-oriented analytic procedure" (Patzelt et al. 2014) which continued until the codes were deemed satisfactorily representative of the content of the primary data source.

\section{Defining theoretical subcategories and categories}

The next step involved raising the level of abstraction by moving from coding of transcripts to a more conceptual aggregation of codes into theoretical subcategories, referred to as axial coding (Locke 2001; Strauss and Corbin 1990; Patzelt et al. 2014). For instance, for the purposes of isolating origins of early suppliers, codes relating to the theme 'sources of suppliers' were grouped together under subcategories such as "founders as source of supply", "suppliers from word-ofmouth", "equity partnership as a source of suppliers" and so on, see Fig. 1. Having subcategorized and categorized all the codes deemed relevant for the purpose of the study, the data was next organized into summary tables where the rows represented each subcategory, the columns represented the cases (the ten firms) and the cells specified which case the subcategory was relevant to. By relevant here is meant that the case contained one or more codes which fit into that subcategory. The summary tables allowed for comparison of the differences and nuances between codes within subcategories across the cases in which the codes appeared. For example, under the theoretical subcategory "suppliers from personal networks" the codes represented three different firms' relationships with suppliers from founders' personal networks, with variance in managers' perceptions of early supplier relationships, strategies, motivations and so on. Here, instances of within-case variance were compared on a case-by-case basis both from the primary data (interviews and field notes) and secondary data (the Proff financial database and information acquired from Internet searches).

\section{Aggregating theoretical dimensions}

The final step of the data analysis process raised the level of abstraction further, from subcategories and categories into socalled 'aggregate theoretical dimensions' (Gioia et al. 2013), combining constructs into larger themes. This process involved evaluating each theoretical concept and iterating again between the data and the emerging dimensions to examine fit (Glaser and Strauss 1967; Locke 2001; Patzelt et al. 2014). Figure 1 provides a visual summary of the three-step data analysis process, showing examples of first-order codes, theoretical subcategories (sources) categories (relationships) and aggregate theoretical dimensions (timing).

\section{Limitations}

Interviews as a source of data is susceptible to limitations relating to bias due to poorly articulated questions, response bias, reflexivity (saying what the interviewee thinks the interviewer wants to hear) and inaccuracies due to poor recall. The use of semi-structured interviews and open-ended questions worked to mitigate the effects of some of these limitations. Given that the focus of the interviews was on events from as far back as five years prior to the interviews, managers' ability to recollect and recount events with a high degree of accuracy should for this study also be considered a limitation (Yin 2014). Although articles, press releases/blog- and social media posts as well as archived versions of the firms' websites were used to attempt to verify the validity of the statements gathered during interviews, a better source of data might have been interviews with early participants. This would also have made the findings more robust and of higher resolution, as factors such as motivations and preferences could have been examined more deeply. Such interviews were however not feasible as a consequence of the design of the study and its 'post-hoc nature', a consequence of wanting to capture data from firms whose platforms were likely to have reached 'critical mass', i.e. had created a liquid enough market to permit sustainable growth (Ondrus et al. 2015). The fact that coding and analysis was conducted by a single researcher should be considered an additional potential limitation to the validity of the analysis. In particular, the process of moving from statements to first-order codes, to theoretical sub-categories and so on, 'raising the level of abstraction', would likely have benefitted from an additional researcher whose interpretations and categorizations may have differed. Other limitations unique to the study included those associated with the objects of study (start-up companies), which inhibited the researcher's ability to review potentially useful quantitative data on the effectiveness of the firms' purported strategies, as most of this data was either never captured by the firms, or since lost.

\section{Findings and analysis}

The findings of the study shed light on the question "How do managers of nascent intermediary platforms in two-sided markets strategize to recruit early suppliers?". The following analysis explores three fundamental questions: 1 . How were 


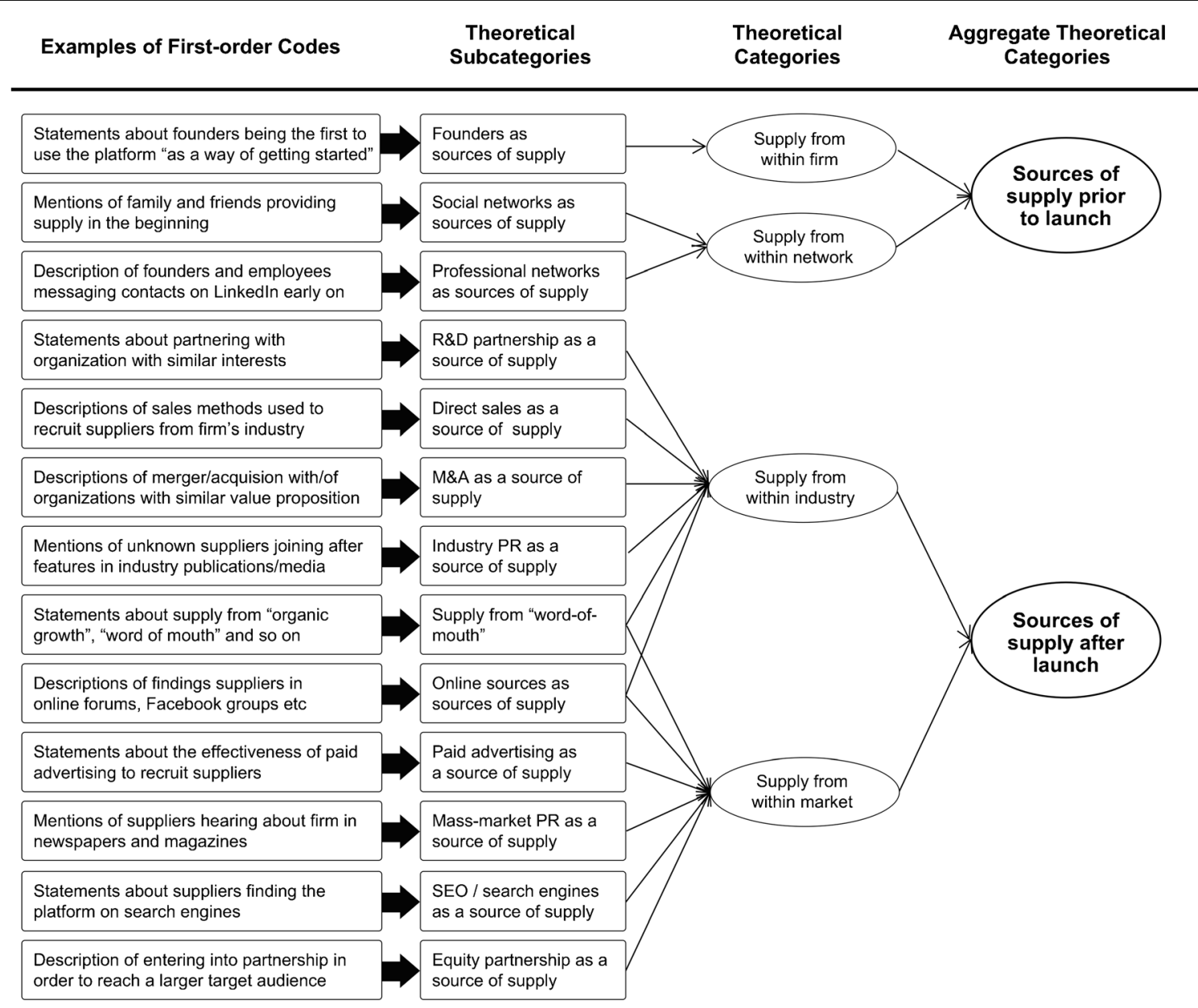

Fig. 1 Examples of the how the theoretical constructs evolved using the so-called 'Gioia-method' of data analysis (Corley and Gioia 2004; Gioia et al. 2013)

suppliers recruited? 2. What were suppliers' relationships to the firms they were recruited to? and 3. When did suppliers join? The findings are presented in a conceptual model according to the timing of when suppliers joined, prior to and post launch, in Fig. 2. As several of the managers described a "slow rollout", "multiple launches" and "a beta period", the term "prior to launch" in this setting is meant to generalize the concept 'prior to having established recurring demand'.

\section{Suppliers prior to launch}

Managers of six firms mentioned a role for within-firm, "firstparty" supply of goods and services prior to launch. In two of these cases, at Tise and Uninite, this was motivated mainly by founders' desire to ensure that as their services launched, the platforms "wouldn't be empty". The manager of the former, a social marketplace for buying and selling used goods, describes "starting with us and everyone around us downloading and starting to list items so there would be some content". At the latter firm, which provides a roommate matching service, the manager described "I put my own apartment up for rent. [The] person we ended up choosing would get one month free rent. We made a contest out of $i$, and were buried in requests". In other cases, the identification of founders as potential early suppliers occurred prior to the founding of the firms themselves. For managers of the graphic design platform Graphiq, part of the motivation for choosing to start a design service came as a result of the observation that one of the founders himself could provide the initial supply in order to get the platform started. The manager describes the use of a within-firm early supply strategy as successful, stating that it was "critical for us to get our first sale", stating that even before the firm was founded "in the design industry, we saw a very short path to getting the first sale". In terms of motivation, at the private tutoring service LearnLink the founder similarly explained how his own first-hand experiences with the deficiencies of existing tutoring services inspired him to start a better platform where he himself could tutor students more effectively, and that this was how the firm successfully launched. The manager also reported a requirement for employees to also teach, that "everyone has to have at least one student in order to get paid", and that he himself as CEO "have had students continuously for five years now, [...] sometimes up to 9-10 students at once". The same manager 


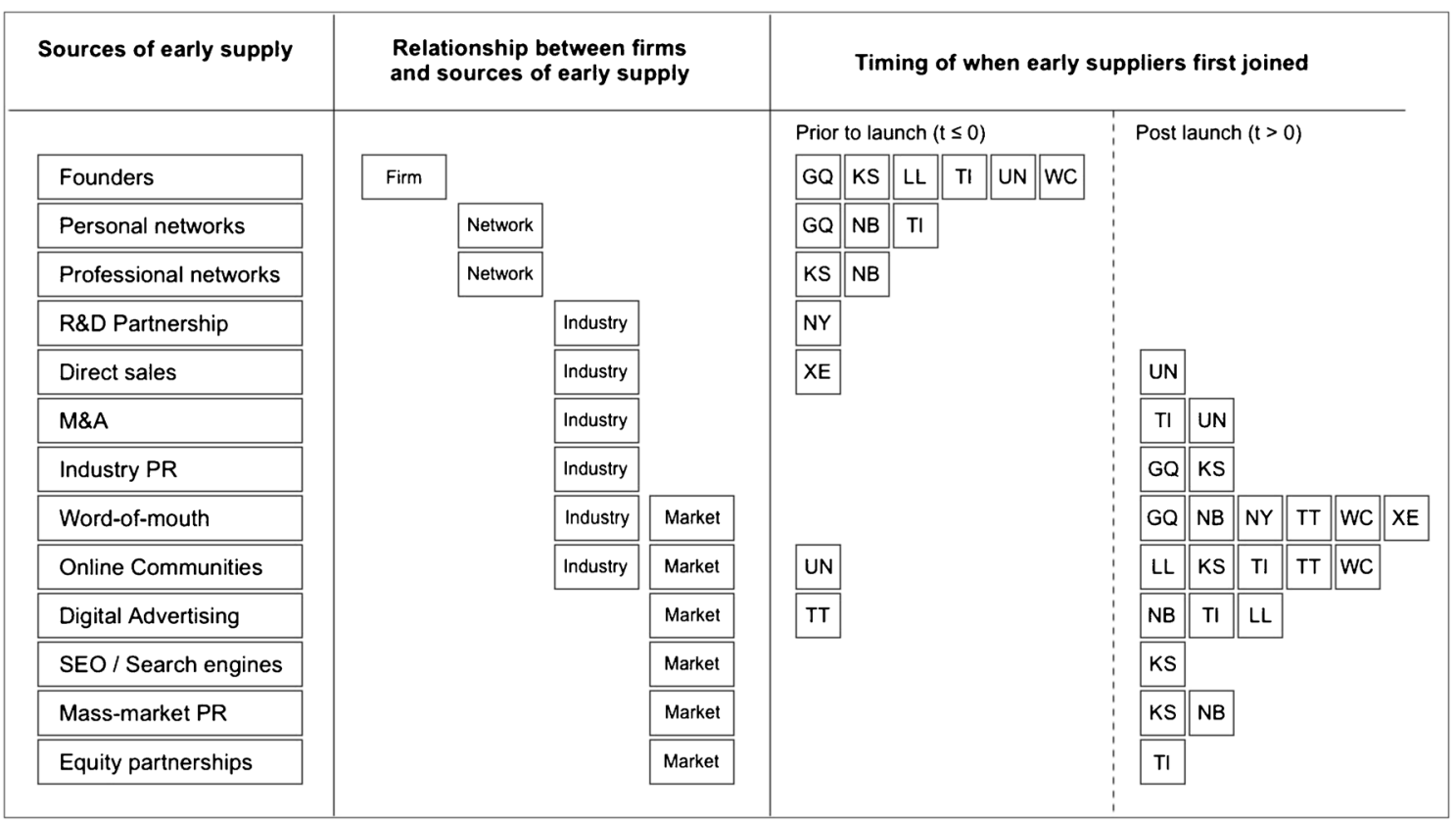

Fig. 2 Overview of firms' strategies for recruiting suppliers in terms of sources, relationships and the timing of when suppliers joined

also expressed great personal motivation from tutoring for its own sake. At the other platform for graphic design/marketing services, Konsus, managers' reasoning for utilizing withinfirm supply was different: founder-provided supply was described as a means of meeting peak demand, a secondary "backup" source used when the firm was unable to adequately match demand from its primary source of early suppliers (freelancers from their professional networks), stating that in the beginning, "we always tried to find freelancers, but if you have short deadlines then sometimes you have to do it yourself". Yet again different, at WeClean, having founders provide supply to the platform (cleaning services) was described as a part of the company ethos - that the founders believed strongly in the principle that everyone at the firm needed to experience suppliers' role in order to gain valuable first-hand experience with the business they were in, stating that in the beginning "We did the majority of the cleaning ourselves.", and even during the time of the interview (when other suppliers had joined), "everyone who is an owner in the company is out there cleaning" because "cleaning is the backbone of what we do, and we never want to forget that, it's what grounds us".

Managers of four firms mentioned early supply of goods and services originating from the founders' personal- and professional networks prior to launch. At all four firms (Graphiq, Konsus, Nabobil and Tise), recruiting suppliers from networklevel sources was described as part of the firms' primary strategy for acquiring early suppliers. At the design service Graphiq, the founders early on reached out to freelance designers in one of the co-founders' personal network, whom the founder said he "knew I could get on board early". At the design/marketing service Konsus, the platform was first launched by one of the co-founders manually intermediating communication between interested clients (SMEs) in Norway and freelancers in the Philippines whose services the manager himself had used in the past. "Mostly, I'd guess about 20 percent we were unable to match in the beginning", the manager stated. Similar to the reasoning provided by the founders of the social marketplace Tise, the CEO of the car sharing service Nabobil described how everyone in the firm reached out both to people in their personal and professional networks via Facebook and LinkedIn asking for a favor to "help us get started" and "build up some volume". Regarding the effectiveness of the strategy, the manager stated that it "got us started".

Four firms recruited suppliers from industry- and marketlevel sources prior to launch. These were NyBy, Xeneta, Uninite and TikkTalk. At Nyby, the platform for organizing community tasks, the firm's sole entry strategy was to enter into research and development partnerships (R\&D) with a municipality and a church mission which both "wanted to join right away" and so agreed to license the platform once it was developed and provide both suppliers and users from their organizations and professional networks. Speculating about why the organizations decided to join so "early", the manager stated that they "had for ten years been talking about needing to think different, the health care system of tomorrow, municipalities 3.0 and so on", suggesting that NyBy's initial suppliers were in the market for a solution similar to that which they were proposing, prior to being approached. The manager describes using an "R\&D loophole [...] which allowed us to get paid ahead of time, over the regular threshold, as long as 
we are solving a problem the organizations needed to get solved". At the freight price benchmarking platform Xeneta, prior to launch the founder described entering their first meeting with "nothing", adding "you're selling the story, right?". Despite this, the manager describes being able to recruit firms to both provide supply (in the form of prices disclosed in confidential contracts) and to eventually use their service, exclusively from "traditional" sales methods such as cold-calling and sales meetings. The firm built web scraping software to generate leads among users of the social network LinkedIn who worked for firms who might be interested in the platform they were building. The manager explains "in the beginning, we cold-called. [...] Within two weeks, I had booked meetings with approximately eight of the ten largest [firms] we had picked out, and then just traveled around. More of less all of them provided some [pricing] data". Regarding suppliers' motivations, the manager said, "I think the pain they were feeling was pretty severe", adding "What made it interesting was the fact that this was confidential data, which is both what made it valuable and extra hard to get".

At the roommate matching service, Uninite, in addition to founder-provided supply, the manager describes "building up a database of property owners, who we would call". When asked how they established the database of suppliers, the manager responded, "They were people who had ads in other places, who we approached", summarizing their value proposition to landlords as akin to "You'll get twice the exposure". Finally, at TikkTalk, the manager described supplier recruitment as somewhat of a trivial pursuit using a strategy consisting exclusively of paid digital advertising, stating "Translators we found quite easily. We tried some Facebook Ads and it was super easy to attract them onto the platform. They are all looking for jobs".

\section{Suppliers post launch}

After having established recurring demand from their early sources of suppliers, in addition to/replacement of existing sources, nine of the ten firms describe recruiting additional suppliers from industry- and market-level sources. Firms that continued their existing strategy of recruiting suppliers through direct sales methods were Xeneta (cold calling and sales meetings) and NyBy (R\&D partnerships with municipalities, charities and other non-profit organizations). Having established "a foundation to build off" from suppliers originating from within firm- and network-level sources, six firms described recruiting from industry-level sources to expand their service further. At the social marketplace Tise, the firm supplemented its initial group of firm- and network-level suppliers by "working from Facebook buy-and-sell groups for a while", some of which "had over two hundred thousand

\footnotetext{
${ }^{3}$ Web scraping software is software used for extracting data from websites
}

members". The strategy eventually led to Tise merging its platform with the owner of two popular groups, who in return received "a stake in the company". In order to maximize the value provided by these early suppliers, Tise's CEO noted how they deliberately chose to hide the publication date of when items for sale were posted, so that the platform wouldn't "feel dead". The roommate matching service Uninite utilized a similar strategy of working from Facebook groups, but rather than giving up equity ownership chose to acquire two groups outright from their owners in order to expand the reach of their service.

At both of the graphic design services (Graphiq and Konsus) managers mentioned exposure in industry publications as valuable sources for recruiting additional suppliers post launch. Regarding its feature in an industry magazine, Graphiq's manager stated "That hit the nail on the head. After that suddenly a bunch of designers we didn't know started signing up". About the motivations of these designers, the manager stated "They are typically young, fairly sophisticated technically, using the newest tools. They work freelance 100\%, which they do because they want to be free, they love what the freelance-lifestyle has to offer". By a similar mechanism, at Konsus the manager described how the firm received "a lot of attention in the media", stating "people wrote blog posts about the best freelancing-websites, why and whatnot". About freelancers' motivations for choosing to join their platform, the manager stated "They without a doubt love the flow of already-defined, incoming already-priced projects that they can just start working on" and added "it wasn't that hard to get them to sign up because it really just gives them an optional way of landing work. Most freelancers have a very multichannel approach. [..] When requests come in, it's sort of like 'Okay. If available, say yes. If not, say no.'". The manager described the additional incentive of a "career-path" that "leads to ownership of shares of Konsus Inc". Among firms recruiting suppliers from online communities such as internet forums, blogs, job listing boards and so on, Konsus' manager described "Having lots of ads on job boards around the world for all the positions [...] we recruit for" and similarly at the tutoring service LearnLink, where the manager stated that by the time of the interview "It's very easy for us to get tutors, they're just [university] students. We post on online class groups, buy-and-sell groups for books", adding however that "There is a limit to how much we can keep spamming these groups". The manager also highlighted that even though there were "plenty who are interested, we then have some requirements like police certificate of conduct and so on, which leads many to 'fall off'. Then there's the interview, and getting students. A fair amount fall off along the way" adding "We're obviously working on lowering the friction, but we also think that [friction] can kind of work to sort out those who aren't that interested, because they're not going to be very good tutors anyway". In addition to the translation service 
TikkTalk, among the firms utilizing paid digital advertising, Tise's manager mentioned using Instagram Ads early on as a way of "letting some volume build up" among suppliers who have a "passion for reuse" and who enjoy the social activity of following, buying and selling used items from "people whose style they relate to". At the car sharing service Nabobil, paid advertising as a source of recruiting suppliers was described as being part of a "sophisticated marketing-run", which included "Facebook [which] worked well as a push-channel". The manager at Nabobil also highlighted the value of being "lucky to get a lot of PR, which helped a lot". Other firms which recruited early suppliers through PR at the market-level included Konsus, whose the mentioned "having a fair bit of PR in Business Insider, Wall Street Journal, TechCrunch and so on", however also pointing out that "Actually now most of the left side of the funnel comes through SEO, we have a hundred thousand visitors to our website every month". The final identifiable market-level source of early suppliers mentioned by managers was the equity partnership Tise entered with a Norwegian public figure ("influencer") who "went out and talked about us in her channels [...] which helped a lot".

Finally, six of the firms mentioned eventually recruiting suppliers from "word-of-mouth" specifically, potentially as the consequence of emerging direct and/or indirect network effects. Two firms mentioned word-of-mouth in their industry as an important way of recruiting additional suppliers post launch, including at Graphiq where it was described that "We do very little marketing but new designers keep signing up", and at NyBy where "several other [organizations] heard about it and came to us to be development partners". Three firms mentioned general/market-level word-of-mouth as an important source for recruiting early suppliers. Nabobil's manager vaguely described that early on, their main task was "telling Norway that now it's possible to rent a car right where you live", and that as suppliers began completing transactions "then people start talking about it". By the time of the interview, the manager stated that "the primary source of growth is [now] organic, that car owners talk about it, that they are happy, that car renters talk about it, that they're happy" adding about preferences and motivation that in the beginning, suppliers had a general attitude of "if it works, it works, if it doesn't, it doesn't", but that after a while, more and more began expecting to make money off renting out their car, indicating that suppliers' expectations about demand on the service could change over time. At the cleaning service WeClean, the founders described how word-of-mouth/organic recruitment of suppliers accrued from "the soft communication we're doing [which] maybe only hits four people, but it hits those four", adding "they become ambassadors for us". Finally, at the translation service TikkTalk the manager described eventually "shutting down Facebook Ads" and "still getting about 5-10 sign-ups per week, [...] organically", and that "we [also] had people online just finding us, and creating accounts, [...] just random people somewhere on the Internet, I don't know where they heard about us, but they found us". About suppliers' preferences, TikkTalk's manager highlights that "interpreters love the steady stream of jobs because they [generally] don't know where next month's rent is coming from" (Table 2).

\section{Discussion}

Firms looking to establish platform businesses in two- and multi-sided markets are said to face the initial challenge of recruiting buyers and sellers whose participation decisions are mutually dependent (Spulber 2010). And so, to overcome this 'circular conundrum' (Spulber 2010), at launch managers of platform firms invest to create an ecosystem of 'complementors' who commit their resources to support one or more platforms over time (Venkatraman and Lee 2004; De Reuver et al. 2018). The goal of such initial entry strategies is hence thought to be to assemble sufficient numbers of participants to reach a so-called 'critical mass' (Evans and Schmalensee 2010) to enable a liquid enough market to permit sustainable growth (Ondrus et al. 2015) via word-of-mouth and other mechanisms fueled by positive network externalities.

Findings from ten established two-sided platform firms in Norway suggest that the viability of nascent platform firms' entry strategies is reliant on both organizational and contextual factors, whose details vary on case-by-case bases, but whose underlying managerial considerations have much in common. The discussion below grounds these findings to predictions from extant literature and where appropriate, highlights empirical findings which have yet to be explored theoretically. The discussion is structured according to the strategic considerations expressed by managers of the firms included in the study. These considerations include 1) The management of expectations and 2) The governance of supply.

\section{The management of expectations}

Users' expectations about the level of participation in twosided markets has previously been shown to be an important antecedent of direct (same-side) network effects (Fuentelsaz et al. 2015). That is, before a dominant platform emerges, potential participants in two-sided markets are assumed to be more likely to prefer the platform they believe will be the market leader in the future (Caillaud and Jullien 2003; Katz and Sharpio 1994). Extant literature hence predicts that new entrant platform firms have strong incentives to signal and condition potential participants' expectations about their future dominance (Chintakananda and McIntyre 2014). Accordingly, pre-announcing a new platform before it is functional may catalyze initial adoption by raising expectations among a sufficiently large number of people to where, once 
Table 2 Early supplier recruitment strategies by timing and relational proximity to firm

\begin{tabular}{l} 
Prior to launch \\
\hline Graphiq \\
Supply from founders and personal network example: \\
"The main reason we choose [to start a platform for \\
designers] was that here we had some \\
domain-specific knowledge and at least, I was a \\
designer and could potentially do projects myself \\
and I knew people I could get onto the platform \\
immediately. [In response to the question "Who \\
were the first designer on your platform?"]" It \\
was me, hehe. It was me and friends of mine from \\
design school."
\end{tabular}

Graphiq The main reason we choose [to start a platform for immediately. In response to the question "Who were the first designer on your platform?"] " It design school.'
Supply from founders and personal network example:

\section{Relationship}

Post launch

Graphiq

Firm Network

Supply from Industry PR example:

"I think the first external was a local designer who I had never met before [...] Early on we got an article in Grafill, which is an industry publication for graphic designers[...] That hit the nail on the head. After that suddenly a bunch of designer we didin't know started signing up."

Supply from word of mouth example:

“We've rarely had problems getting enough designers [...] So now, it's really just word-of-mouth, we do very little marketing but new designers keep signing up."

\footnotetext{
Konsus

Supply from professional network example:

"I sort of had my own freelancers that I had worked with in the past. Not very many, but, I knew two women who used to help me with PowerPoint [...] from the Philippines. We used them in the beginning [...] I would say like" Hey, can you help a friend with this job?'. Eventually we started doing it in a more structured way.'

Supply from founders example:

"I mean, I did a fair bit of Powerpoint and various other boring data-gathering and stuff in the beginning. Of course we tried all the time to find freelancers, but if you have short deadlines and such, you have to do it yourself."
}

LearnLink

Supply from founder

"I eventually just thought 'okay, I'll just put something up on the web and start my own thing." I ended up getting lots of request, which made me think 'okey, there's room for new solution here' [...] I've been a tutor continously now for five years [...] right now I only have one, but there have been periods when I've had 9-10 students simultaneously."

Nabobil

Supply from personal and professional network example:

"The first thing we did was that everyone at Nabobil sent out a message on Linkedin and Facebook to everyone we knew and said 'Hi, I'm starting a new firm and need your help to get started".
Network

Firm

Firm

Konsus

Supply from online source example

"What we do is that we have lots of ads on job boards around the world for all positions. For all six categories we recruit for. Then they come to our website"

Supply from industry PR example:

"We do get a lot of attention. people write blog posts about the best freelancing-websites, why and whatnot"

Supply from mass-market PR example:

"People read about us in blogs and newspapers, and we've had a fair bit of PR in Business Insider, Wall Street Journal, TechCrunch and so on"

Supply from SEO / search engines example:

"Actually, now most of the left side of the funnel comes through SEO, we have one hundred thousand visitors on our website every month"

LearnLink

Supply from online sources example:

'It's very easy to got tutors. They're students. [We] post on class groups, buy-and-sell groups for books, and get a lot of visitors [from this]"

Supply from paid advertising example.

[In response to the question "Are you using paid adverting?'] "We're starting somewhat now because there's a limit to how much we can keep spamming these groups, we get kicked off eventually."

Nabobil

Supply from paid advertising example:

Network

"We use the digital channels and have a very sophisticated marketing-run, where we think in terms of a funnel. We know who is in the funnel, where they are [...] Facebook has worked well as a push-channel [for recruiting suppliers].”
Industry

Relationship

Industry

Industry

Industry

Industry

Market

Market

Industry 
Table 2 (continued)

Supply from mass-market PR example:

"We were lucky to get a lot of $P R$, which helped a lot. We've also been lucky because Airbnb succeeded and now people get what if is, easily."

Supply from word-of-mouth example:

"Nabobil pulled of what Arbnb pulled off, which is having the primary source of growth being organic. That our car owners talk about it, that they are happy, that our car renters talk about it and that they're happy."

NyBy

Supply from R\&D partnership example

"I made an ugly Powerpoint presentation and started in Asker, because that's where I'm from. They signed up immediately. Both the political side and went to Oslo Church city mission and they also wanted to join. So then we had 2/2 amazing! And they were willing to pay in advance."

TikkTalk

Supply from paid advertising example:

"Translators we found we found quite easily. We tried some Facebook Ads it was super easy to attract them onto platform. They are all looking for jobs."

Tise

Supply from founders and personal networks example:

"We started with us and everyone around us downloading and starting to list items so that there would be some content [...]". the city administration were super excited. Next I

Firm

Market

Firm Network

Uninite

Supply from founder example:

"It started with me using it myself, so I put my apartment up for rent. The [renter] we ended up choosing would get one month free rent. So we made a contest out of it and were buried in request."

Firm
NyBy

Supply from word-of-mouth example

"We didn't do any marketing, because we already had two partners and wanted to work with them. But then Bcerum county heard about it as well, several other boroughs heard about it, The Church City Mission heard about it, Gjensidge heard about it, several of them heard about it and came to us to be development partners. They financed our development up until the point where we could raise external funding".

TikkTalk

Supply from word-of-mouth example:

"We actually shut down Facebook Ads seven months ago [...] and we still get about 5-10 signups per week on its own.'

Supply from online sources example:

"Actually, we [also] found people just online finding us, and creating accounts, [...] Those were not even Facebook ads, those were just random people from somewhere on the internet. I dont know how they heard about us but hey found us."

Tise

Supply from paid advertising example:

"[...] We then got some more through advertising. Then we left it alone for a while and let some more volume build up. then went ahead with more advertising. At the end we had aroud 10000 users".

Supply from equity partnership:

"We launched, and at the same time as we spent a fair amount of money on advertising. Jenny went out and talked about us in her channels, which lead to us converting a fairy large number of users quickly."

Supply from online sources and M\&A examples:

"At one point we tried to work from Facebook "buy and sell" groups. [From this] we've acquired a huge reach [...] [We did it] in order to get their target audience, these groups had 200.000 members all put together. [...] He became part of the company, he owns a stake in the firm".

Uninite

Supply from direct sales example:

[In response to the question 'How do you recruit landlords?'] "Landlords are hard. It's a target group that isn't very digital. That often is of the older guard. So.. Sales meetings."
Market

Market

Industry

Market

Market

Market

Market

Industry

Industry 
Table 2 (continued)

\begin{tabular}{|c|c|c|c|}
\hline Prior to launch & Relationship & Post launch & Relationship \\
\hline & & $\begin{array}{l}\text { Supply from M\&A example } \\
\text { "We own the group for [rental] apartments in } \\
\text { Bergen, the Facebook group with something like } \\
\text { twelve thousand users. [...] We bought it [...] and } \\
\text { own two. We own the largest both in Bergen and } \\
\text { Trondheim." } \\
\text { Supply from online sources example } \\
\text { "We [also] built up a database of landlords over time, } \\
\text { that we called - who we knew had ads in other } \\
\text { places. We basically just called them [...]. and said } \\
\text { Hey, you'll get more exposure. }\end{array}$ & Industry \\
\hline WeClean & & WeClean & \\
\hline $\begin{array}{l}\text { Supply from founder example: } \\
\text { "We did most of the cleaning. [...] Cleaning to us is } \\
\text { the backbone of what we do, and we never want to } \\
\text { forget that. It's what grounds us." }\end{array}$ & Firm & $\begin{array}{l}\text { Supply from word-of-mouth example: } \\
\text { "I think it's the soft communication we're doing. It's } \\
\text { not a call to action, we just put it out there. Maybe } \\
\text { everyone isn't reading what we're writing, maybe } \\
\text { only four people, but it hits those four. They } \\
\text { understand what we're talking about, what we're } \\
\text { trying to say, what we're working with. Then they } \\
\text { become ambassadors for us. [We think] that's } \\
\text { much more valuable than two hundred likes on a } \\
\text { superficial [...] photo." }\end{array}$ & Market \\
\hline $\begin{array}{l}\text { Xeneta } \\
\text { Supply from direct sales example: } \\
\text { "In the beginning we cold-called. The approach that's } \\
\text { always worked fairly well is to first get a hold of } \\
\text { the right person and[...]tell them that you've built } \\
\text { something they can offer a qualified opinion of. } \\
\text { [...] Within two weeks I had booked meetings with } \\
\text { approximately eight of the ten largest [firms] we } \\
\text { had picked out, and then just traveled around. } \\
\text { More or less all of them provided some data" }\end{array}$ & Industry & & \\
\hline
\end{tabular}

the platform does launch, participants' expectations are favorable (Bhargava 2014).

Managers of several of the firms included in the study discussed strategies aimed at raising the expectations among potential supply-side participants prior to launch. For instance, at both Graphiq, Konsus and Nabobil, approaching industryand mass-market publications allowed the firms to announce the existence of their platforms early on to a wide audience, which according to the managers resulted in increased recruitment of suppliers. In the cases of Graphiq and Konsus, the strategy was described as viable due to context-specific factors, in that they operated in industries populated by freelancers who "are always looking for work" and "have a very multi-channel approach". Viewed in the context of extant literature, the managers' view was hence that sufficient numbers of (typically) designers were willing to join their platforms despite having no, neutral, or even unfavorable expectations about their future dominance. A similar dynamic was expressed in the market for translation services by the manager at TikkTalk, who described "trying some Facebook Ads", which was sufficient to attract enough early suppliers for the platform to launch, again because the participants the platform catered to were "are all looking for jobs". Similar contextual factors were also described as enabling in the markets for personal tutoring- (LearnLink) and cleaning services (WeClean), also both catering to markets populated largely by freelancers looking for work on their supply-side. In the cases of Konsus and Nabobil, their strategies of raising expectations through mass-market publications were additionally enabled by firm-specific factors, namely participation in the renowned start-up accelerator program Y Combinator (Konsus) and the CEO's notoriety from his previous employment as a country-manager at Airbnb (Nabobil), which both helped garner the attention of mass-market media outlets.

Perhaps most uniquely, though, were the findings from interviews at Xeneta and NyBy whose managers both testified to approaching their initial sources of early supply without necessarily raising expectations, but rather simply 'offering an alternative to existing solutions'. When the CEO of Xeneta for instance approached the platforms' first prospective suppliers with "nothing", except merely "selling the story", he was indeed able to book "meetings with approximately eight of the ten largest [firms]" they had approached, "more or less all of [whom] provided some data". Similarly, when the manager of NyBy approached their first two potential suppliers, he described both agreeing to "join right away", 
and to getting "paid ahead of time, over the regular threshold" due to what he described as an "R\&D loophole". Neither manager described exaggerating the platforms' current status in terms of viability, as extant theoretical predictions have at times warranted (Bhargava 2014). In both cases however, the managers described the existence of contextual factors which enabled their strategies to work, namely pronounced demands for new solutions among the firms they were approaching, described by the manager of Xeneta as a certain "pain they were feeling [which] was pretty severe". At Xeneta, a firm-specific factor potentially enabling the success of the strategy was the CEO's six-years of experience working on the supply-side of the firm's industry.

In extant literature, the managerial challenge of overcoming unfavorable expectations among potential participants is often addressed as a signaling problem (Fuentelsaz et al. 2015) which may be framed as either quantitative (Evans and' Schmalensee 2007; Brynjolfsson and Kemerer 1996) or qualitative (Katz and Sharpio 1994). Underlying - but rarely addressed — in such theoretical debates is however the more fundamental dynamic of two-sided demand in platform-based markets. That is, that although in traditional markets conceptualized as a one-sided phenomenon, in two-sided markets the demand for the platform itself' can be two-sided phenomenon. In several of the cases described above, managers less so expressed needing to 'raise expectations about the future dominance of their platform' (Bhargava 2014) but instead simply 'offering an alternative to existing solutions', a function of the level of demand among the individuals, firms and organizations they were approaching to participants. The mere existence of the potential of their proposed service (on one or both sides of their markets) seems to have been an adequate signal to garner sufficient interest and participation among such participants. At Graphiq, Konsus, LearnLink, TikkTalk and WeClean, properties of the participants on the supply-side of their markets - populated by freelancersenabled them to rather easily attract sufficient numbers of applicants to ensure that any potential chicken-and-egg problem had been overcome. Similarly, as a function of their demand for new solutions, buyers of freight services and organizers of community tasks were willing to buy into Xeneta and Nyby's respective value propositions prior to their establishments of viable platforms, enabling them to overcome any potential chicken-andegg problems which theory may have predicted could occur (e.g. Caillaud and Jullien 2003; Hagiu and Spulber 2013).

In relation to extant literature, the implications of these findings are that in addition to the quantitative signaling of e.g. the size of an installed base (Evans and Schmalensee 2007), the early achievement of a large market share (Brynjolfsson and Kemerer 1996) or the qualitative signal of brand value or reputation (Katz and Sharpio 1994), in markets featuring certain contextual characteristics related to the demand for new solutions, the signaling of a new platform in itself may be sufficient to successfully enter such markets.

\section{The governance of supply}

Increasingly, there seems to be consensus among management scholars emphasis on the management of supply is particularly beneficial in network markets (Kapoor and Lee 2013). The technology management literature has here previously focused on how the decisions of platform owners regarding the 'openness' of their platform influences innovation through the platform's ability to attract supply-side participants (e.g. Boudreau 2010; Eisenmann et al. 2009). Herein, various topics studied include the level of access to information a platform allows for its participants, as well as the cost of this access and the rules governing its use (Gawer 2014). Studies have for instance highlighted the trade-offs between open and closed platforms (Gawer and Cusumano 2008; Eisenmann et al. 2009). As some researchers have argued that a small lead in attracting early customers could tip the market in the favor of an early entrant with an inferior product or service (Shapiro and Varian 1998), the degree to which managers choose to open their platform could be an important factor in its ultimate success. As such, much of the theoretical debate surrounding the effectiveness of entry strategies in two- and multi-sided markets has thus far revolved around the rapid building of a large network of supply- and demand-side participants (Evans and Schmalensee 2007; Ondrus et al. 2015). This because, as traditionally conceived, an increase in network size increases the value for all users in the network (Katz and Shapiro 1985; Farrell and Katz 2000).

\section{Availability/Specificity}

Some researchers have gone as far as claiming that the size of the installed base is the most strategic asset in network industries (Evans and Schmalensee 2007) because users value platforms with a larger user base more than those with fewer users (Cennamo and Santalo 2013). Interestingly, nascent previous research has however also suggested the opposite, that installed base is not a necessary condition but rather, that even at low levels of participation from suppliers, demand-side participants were responsive to effective recruitment strategies Shankar and Bayus (2003). The findings of this study, perhaps by the nature of its design, tend to lend more credence to the latter claim than the former.

Intuitively, one would think a key consideration for managers formulating effective entry strategies would be to make note of the relationship between the specificity of the platform's value proposition to its demand-side participants and the availability of necessary supply needed to enable such a service. That is, inherently, higher degrees of specificity of supply certainly correlates to lower availability of such supply, as 'suppliers fulfilling higher degrees of specificity' is a subset of 'suppliers fulfilling lower degrees of the same specificity'. A ride-sharing service requiring suppliers to 'own a car' is able to recruit from a larger pool of potential drivers than a ride-sharing service requiring 
suppliers to 'own a Tesla Model S which is newer than two years and has leather seats', for instance. From the findings of the study, on the one hand, Tise's value proposition as a marketplace where demand-side participants can purchase second-hand fashion goods or WeClean's value proposition as a cleaning service where demand-side participants can hire independent cleaners, put few limitations on their availability of supply. Xeneta's demand-side value proposition as a freight price benchmarking service or Uninite's value proposition as a roommate matching service, on the other hand, put more limitations on availability. Stated more colloquially, platforms operating in niches have more potential supply-side participants available for recruitment.

Interestingly, in this study this inherent contextual factor (specificity vs availability of supply) seemed to correlate poorly with predictions about the eventual success of the firms' entry strategies. Managers of platforms which arguably recruited from large pools of potential supply-side participants (Graphiq, Konsus, LearnLink, Nabobil, Tise, WeClean) described many of the same challenges related to the formulation of successful entry strategies as managers of platforms with smaller pools of potential supply-side participants (NyBy, TikkTalk, Uninite, Xeneta). In fact, one might argue that if evaluated based on this parameter alone, managers of platforms such as Xeneta, NyBy and TikkTalk were even more effective, only needing to recruit from one or two sources of supply per firm versus typically three to four for firms such as Graphiq, Konsus, LearnLink and Nabobil. Speculating about reasons why, here too, it seems prudent to emphasize the role of the 'demand for new solutions' among participants in the markets the former firms were operating in, in the cases of Xeneta and NyBy on the demand-side (among buyers of freight services and community tasks) and for TikkTalk on the supply-side (of interpretation services).

\section{Quantity/Quality}

Moving beyond the previous - purely quantitative - consideration of the relationship between the specificity and availability of supply, it is prudent to also address the managerial consideration of the qualitative nature of supply. Despite researchers' previous particular emphasis on the size of an installed base (Evans and Schmalensee 2007) and the need to rapidly achieve a critical mass of participants (Evans and Schmalensee 2010; Ondrus et al. 2015), increasingly researchers are also turning their attention to the qualitative aspects of supply. Research on this topic has thus far, in line with intuition, predicted that dominant platforms tend to be those that exhibit the highest quality (Liebowitz and Margolis 1994; Schilling 2002; McIntyre 2011). Even in competition with a platform featuring a large installed base, research has for instance shown that new entrants can threaten incumbents' position if the perceived quality of the incumbent's service is not comparable (Zhu and Ianisiti 2012). Recent calls have therefor been made for the further research into what 'quality' is in the context of platform-mediated networks, as well as when quality matters (McIntyre and Srinivasan 2017). The following observations aim to address parts of these calls.

From the findings of this study, quality-specific issues relating to the effectiveness of the firms' entry strategies were most prominent in interviews with managers catering to freelancers, such as Graphiq, Konsus, LearnLink, TikkTalk and WeClean. Such managers emphasized the need to not only measure and govern their supply-side participants based on qualitative performance, but also in some cases actively offer training (WeClean, Konsus) and certification programs (TikkTalk, Konsus) to ensure that their demand-side value proposition was of high quality, as this was perceived to have an impact on the platforms' ultimate success. Speculating about the relationship between the quality of supply and successful entry, the manager at Graphiq for instanced described initially launching the platform as a marketplace optimized "for choice" but quickly realizing that the managers "weren't quite aware of the size of the market [of designers]", namely that the demand to supply among freelancers was so high, and so that a "matchmaking service" (Evans and Schmalensee 2016), rather than a marketplace might be more attractive to demand-side participants. "As time passed, we realized more and more how large the "freedom" domain is, the freelance movement" and so the firm revised their value proposition to instead offer a curated platform where as a demand-side participant "you aren't met with ten thousand choices. Instead, you're presented only those which are appropriate for you'. The same sentiment was echoed at the platform with a similar value proposition, Konsus, whose manager stated that "we try to put ourselves a level above the quality found on the 'open' freelance platforms", emphasizing "the bottleneck in our recruiting is [...] assessment and onboarding, including training”. At Konsus, more so than Graphiq, the additional firm-specific consideration was its enterprise (rather than SME) focus, due to their "extremely high willingness to pay" despite having qualitative requirements which "aren't necessarily that much higher". In other words, the managers observed that on their demand-side, in the enterprise market, there was a willingness to pay for quality, but only to a certain point. The manager at the tutoring service LearnLink described a recruitment process for private tutors involving similarly qualitative considerations, including both a review of the candidate's academic performance as well an interview in order to ensure that the person had sufficient pedagogical skills, stating that "We actually added more governance as we went along". Here too, the contextual factor at the heart of the consideration was the manager's perception that among demand-side participants, a wide variety of potential tutors was less so desired than a handful of high-quality alternatives and so that the quantity of suppliers would likely not be the ultimate determinant of the platform's eventual success. 


\section{Conclusion}

This study's abductive exploration of platform firms' entry strategies in two-sided markets confirm many of the observations and predictions of extant literature while simultaneously uncovering avenues for future theory building and further research.

Interviews with managers of ten established platform firms in Norway revealed that managers consider both firm-specific and contextual factors when formulating entry strategies. Most prominently, it was found that new entrant platforms may successfully overcome the predicted 'chicken-and-egg problem' with supply-side participants originating from sources within or close to the firm, such as the managers themselves and employees as well as suppliers from the managers' social and professional network. Further, it was found that most of the firms studied employed multiple recruitment strategies, and that managers' initial considerations regarding the need for a certain level of supply often gradually shifted to instead emphasizing the quality of supply, as predicted in some nascent literature. In such cases, managers described rather easily being able to attract suppliers to their platforms, in cases even in the absence of recurring demand. Speculating about reasons why, it is suggested that in such cases the demand for new solutions was so great among potential participants that even the potential of the firms' value proposition was sufficient to stimulate adoption.

\section{Implications for managers}

The findings of the study in particularly imply three important managerial considerations. First, in accordance with predictions from existing literature it is essential for managers to measure and evaluate the demand for "the platform itself' among its potential participants prior to entry in order to be able to gauge the expectations of its intended participants, and so be able to formulate effective entry strategies. Second, if the demand for the platform itself is high among one or both groups of potential participants, the hypothesized chicken-and-egg problem upon entry can potentially be discounted as sufficient numbers of e.g. suppliers may be willing to join regardless of their expectations among demand-side participants, or visa versa. Finally, if the demand for the platform itself is high among one or both groups of potential participants, rather than formulating entry strategies aimed at maximizing the number of suppliers, managers should instead put in place mechanisms aimed at maximizing the quality of its supply, as this appears to be a more important factor in such scenarios.

\section{Agenda for further research}

This study's abductive exploration of platform managers' entry strategies in two-sided markets has both helped confirm certain predictions from extant literature, in addition to revealing avenues for further research. In particular, the study motivates further work in two nascent fields of platform research.

\section{Expectations from a strategic perspective}

Extant research emphasizes the role of expectations in twosided markets, evaluating the potential of new entrant platforms according to potential participants' expectations about the future participation of others. Findings from multiple firms in multiple industries in the study suggested a willingness among both supply- and demand-side participants to join platforms despite having either no, neutral, or perhaps even unfavorable expectations about the future adoption by other participants. Speculating about contextual or firm-specific reasons why this might be so, the discussion in particular emphasizes the role of 'demand for new solutions' among one or multiple groups. However, as the investigation of the expectations of potential participants in multi-sided markets was not the purpose of this study, the topic will need further inductive exploration by future researchers.

\section{The quality of supply in platform-based markets}

The second nascent field of platform research which the study contributes to, is that which questions the previous considerable emphasis which has been placed on investigating the correlation between platforms' level of adoption and its level of participation. Although important in some markets, in others, such as those with considerable demand for new solutions, the level of participation appears to be less so important than the quality of participation. However, as the purpose of this study was not to determine the role of quality in two-sided markets, this too requires further inductive research.

Funding Information Open Access funding provided by NTNU Norwegian University of Science and Technology (incl St. Olavs Hospital - Trondheim University Hospital).

Open Access This article is licensed under a Creative Commons Attribution 4.0 International License, which permits use, sharing, adaptation, distribution and reproduction in any medium or format, as long as you give appropriate credit to the original author(s) and the source, provide a link to the Creative Commons licence, and indicate if changes were made. The images or other third party material in this article are included in the article's Creative Commons licence, unless indicated otherwise in a credit line to the material. If material is not included in the article's Creative Commons licence and your intended use is not permitted by statutory regulation or exceeds the permitted use, you will need to obtain permission directly from the copyright holder. To view a copy of this licence, visit http://creativecommons.org/licenses/by/4.0/. 


\section{References}

Alt, R., \& Zimmermann, H. D. (2019). Electronic markets on platform competition. Electronic Markets, 29, 143-149.

Armstrong, M. (2006). Competition in two-sided markets. The RAND Journal of Economics, 37(3), 668-691.

Armstrong, M., \& Wright, J. (2007). Two-sided markets, competitive bottle-necks and exclusive contracts. Economic Theory, 32, 353380.

Bhargava, H. K. (2014). Platform technologies and network goods: insights on product launch and management. Information Technology and Management, 15, 199-209.

Boudreau, K. (2010). Open platform strategies and innovation: Granting access vs. devolving control. Management Science, 56(10), 18491872.

Boudreau, K., \& Jeppesen, L. (2015). Unpaid crowd complementors: The platform network effect mirage. Strategic Management Journal, 36(12), 1761-1777.

Brynjolfsson, E., \& Kemerer, C. (1996). Network externalities in microcomputer software: An econometric analysis of the spreadsheet market. Management Science, 42, 1627-2647.

Caillaud, B., \& Jullien, B. (2001). Competing Cybermediaries. European Economic Review, 45, 797-808.

Caillaud, B., \& Jullien, B. (2003). Chicken egg: Competition among intermediation service providers. RAND Journal of Economics, 34(2), 309-328.

Carlton, D. W., Gans, J. S., \& Waldman, M. (2010). Why tie a product consumers do not use? American Economic Journal: Microeconomics, 2(3), 85-105.

Cennamo, C., \& Santalo, J. (2013). Platform competition: Strategic tradeoffs in platform markets. Strategic Management Journal, 34, 13311350.

Chintakananda, A., \& McIntyre, D. P. (2014). Market entry in the presence of network effects: a real options perspective. Journal of Management, 40(6), 1535-1557.

Corley, K. G., \& Gioia, D. A. (2004). Identity ambiguity and change in the wake of a corporate spin-off. Administrative Science Quarterly, 49(2), 173-208.

De Reuver, M., Sørensen, C., \& Basole, R. C. (2018). The digital platform: a research agenda. Journal of Information Technology, 33(2), $124-135$.

Eisenhardt, K. M. (1989). Building theories from case study research. Academy of Management Review, 14(4), 532-550.

Eisenmann, T. R. (2006) Internet companies' growth strategies: determinants of investment intensity and long-term performance. Strategic Management Journal, 27(12), 1183-1204.

Eisenhardt, K. M., \& Graebner, M. E. (2007). Theory building from cases: Opportunities and challenges. The Academy of Management Journal, 50(1), 25-32.

Eisenmann, T. R., Parker, G., \& Van Alstyne, M. (2009). Opening platforms: How, when and why? (pp. 131-162). Markets and Innovation: Platforms.

Evans, D. S., \& Schmalensee, R. (2007). Catalyst code: The strategies behind the world's most dynamic companies. Harvard Business School Press.

Evans, D. S., \& Schmalensee, R. (2010). Failure to launch: Critical mass in platform businesses. Review of Network Economics, 9(4). https:// doi.org/10.2202/1446-9022.1256.

Evans, D. S., \& Schmalensee, R. (2016). Matchmakers: The New Economics of Multisided Platforms. Boston: Harvard Business Review Press.

Farrell, J., \& Katz, M. L. (2000). Innovation, rent extraction, and integration in systems markets. The Journal of Industrial Economics, 48(4), 413-432.
Fuentelsaz, L., Garrido, E., \& Maicas, J. P. (2015). A strategic approach to network value in networked industries. Journal of Management, 41(3), 864-892.

Gawer, A. \& Cusumano, M. A. (2008). Platform Leaders. MIT Sloan Management Review. MIT Sloan School of Managmenet: Boston, MA, USA.

Gawer, A. (2014). Bridging differing perspectives on technology platforms: Toward an integrative framework. Research Policy, 43(7), 1239-1249.

Gioia, D. A., Thomas, J. B., Clark, S. M., \& Chittipeddi, K. (1994). Symbolism and strategic change in academia: The Dynamics of sensemaking and influence. Organization Science, 5(3), 363-383.

Gioia, D. A., Corley, K. G., \& Hamilton, A. L. (2013). Seeking qualitative rigor in induc- tive research: Notes on the Gioia methodology. Organizational Research Methodologies, 16(1), 15-31.

Glaser, B. G., \& Strauss, A. L. (1967). The discovery of grounded theory: Strategies for qualitative theory. New Brunswick: Aldine Transaction.

Hagiu, A. (2006). Pricing and commitment by two-sided platforms. The RAND Journal of Economics, 37(3), 720-737.

Hagiu, A. (2009). Two-sided platforms: product variety and pricing structures. Journal of Economics Management Strategy, 18(4), 10111043.

Hagiu, A., \& Halaburda, H. (2014). Information and two-sided platform profits. International Journal of Industrial Organization, 34, 25-35.

Hagiu, A., \& Spulber, D. (2013). First-party content and coordination in two-sided markets. Management Science, 59(4), 933-949.

Halaburda, H., \& Yahezkel, Y. (2013). Platform competition under asymmetric information. American Economic Journal: Microeconomics, $5(3), 22-68$.

Kapoor, R., \& Lee, J. M. (2013). Coordinating and competing in ecosystems: How organizational forms shape new technology investments. Strategic Management Journal, 34(3), 274-296.

Katz, M. L., \& Shapiro, C. (1985). Network externalities, competition, and compatibility. The American economic review, 75(3), 424-440.

Katz, M. L., \& Sharpio, C. (1994). Systems competition and network effects. Journal of Economic Perspectives, 8, 93-115.

Kyprianou, C. (2018). Creating value from the outside in or the inside out: How nascent intermediaries build peer-to-peer marketplaces. Academy of Management Discoveries, 4(3), 336-370.

Liebowitz, S. J., \& Margolis, S. E. (1994). Network externality: An uncommon tragedy. Journal of Economic Perspectives, 8(2), 133-150.

Locke, K. (2001). Grounded theory in management research. Thousand Oaks: Sage.

McIntyre, D. P. (2011). In a network industry, does product quality matter? Journal of Product Innovation Management, 28(1), 99-108.

McIntyre, D. P., \& Srinivasan, A. (2017). Networks, platforms, and strategy: Emerging views and next steps. Strategic Management Journal, 38, 141-160.

McIntyre, D. P., \& Subramaniam, M. (2009). Strategy in network industries: A review and research agenda. Journal of Strategic Management, 35, 1494-1517.

Miles, M. B., \& Huberman, A. M. (1994). Qualitative data analysis: An expanded sourcebook. Thousand Oaks: Sage.

Ondrus, J., Gannamaneni, A., \& Lyytinen, K. (2015). The impact of openness on the market potential of multi-sided platforms a case study of mobile payment platforms. Journal of Information Technology, 30(3), 260-275.

Otto, B., \& Jerke, M. (2019). Designing a multi-sided data platform: Findings from the International Data Spaces case. Electronic Markets, 1-20.

Patzelt, H., Williams, T. A., \& Shepherd, D. A. (2014). Overcoming the walls that constrain us: The role of entrepreneurship education programs in prison. Academy of Management Learning Education, 13(4), 587-620. 
Porter, M. (1985). Competitive advantage: Creating and sustaining superior performance. New York: Free Press.

Pratt, M. G., Rockmann, K. W., \& Kaufmann, J. B. (2006). Constructing professional identity: The role of work and identity learning cycles in the customization of identity among medical residents. Academy of Management Journal, 49, 235-262.

Rochet, J. C., \& Tirole, J. (2003). Platform competition in two-sided markets. Journal of the European Economic Association, 1(4), 990-1029.

Schilling, M. A. (2002). Technology success and failure in winner-takeall markets: The impact of learning orientation, timing, and network externalities. Academy of Management Journal, 45(2), 387-398.

Shankar, V., \& Bayus, B. L. (2003). Network effects and competition: an empirical analysis of the home video game industry. Strategic Management Journal, 24(4), 375-384.

Shapiro, C., \& Varian, H. (1998). Information rules: a strategic guide to the network economy. Harvard Business Press.

Spulber, D. (2010). Solving the circular conundrum: communication and coordination in internet markets. Northwestern University Law Review, 104(2), 537-592.

Srinivasan, A., \& Venkamatran, N. (2010). Indirect network effects and platform dominance in the video game industry: A network perspective. IEEE Transactions on Engineering Management, 57(4), 661673
Strauss, A. L., \& Corbin, J. (1990). Basics of qualitative research. Grounded theory procedures and techniques. Thousand Oaks: Sage.

Suddaby, R. (2006). What grounded theory is not. Academy of Management, 49(4), 633-642.

Van Maanen, J. (1979). Qualitative methodology. Thousand Oaks: Sage. Venkatraman, N., \& Lee, C.-H. (2004). Preferential linkage and network evolution: A conceptual model and empirical test in the US video game sector. Academy of Management Journal, 47(6), 876-892.

Wareham, J., Fox, P. B., \& Giner, J. L. C. (2014). Technology ecosystem governance. Organization Science, 25(4), 1195-1215.

Webb, C., Streufort, S., DePadova, A., \& McGlynn, T. (1965). Mixing qualitative and quantitative methods: Triangulation in action. London: Tavistock Publications.

Weyl, E. G. (2010). A price theory of multi-sided platforms. American Economic Review, 100(4), 1642-1672.

Yin, R. K. (2014). Case study research: Design and methods. Thousand Oaks, CA: Sage Publications.

Zhu, F., \& Ianisiti, M. (2012). Entry into platform-based markets. Strategic Management Journal, 33(1), 88-106.

Publisher's note Springer Nature remains neutral with regard to jurisdictional claims in published maps and institutional affiliations. 